\title{
Comunicaciones recibidas
}

Santiago, marzo de 1953

Senior Presidente

de la Sociedad Colombiana de

Obstetricia y Ginecoıgia.

Bogolá.

De mi mayor corsideración:

Tengo el agrado de informar a usled y a la Institución de su digna Presidencia, que la Sociedad Chilena de Obstetricia y Ginecología, en Asamblea General del 16 de diciembre recién pasado, eligió el siguiente Directorio para 1953:

Presidente: doctor Eduardo Bunster M. Vicepresidente: doctor Carlos Ramírez B.

Secretario Generai: doctor Fernando Rodríguez $\mathrm{S}$.

Secretarios anuales: doctor Femando

Figueroa E., doctor Carlos Thonet I Tesorero: doctor Daniel Carril S.

Vocales: doctor Guillermo Galán N.

doctor Aníbal Rodríguez V., doctor

Orlando Trivelli $R$.

Este Directorio reitera el tradicional propósito de la Sociedaj de mantener con vuestra Institución los mismos lazos de amistad y el espíritu de colaboración de siempre.

Lo saluda atentamente,

Dr. Fernando Rodríguez S. Secretario General.
Barranquilla, 4 de marzo de 1953

Señores

REVISTA COLOMBIANA DE

OBSTETRICIA Y GINECOLOGIA.

Bogotá.

Doctores

Ramón Francisco Sánchez y Rodulio Camero Castaño. Directores de la REVISTA COLOMBIANA DE OBSTETRICIA Y GINECOLOGIA. Bogotá.

Estimados colegas y amigos:

Tenemos el horor de dirigirnos a ustedes con el tin de comunicarles que esta Sociedad, en la Asamblea General Ordinaria celebrada el día 27 de febrero recién pasado, eligió dignatarios para el nuevo ejercicio reglamentario, marzo 1953 a lebrero 1954, asi:

Presidente, doctor Fernando Navas Uribe.

Vicepresidente, doctor Sebastián M. Alcalá C.

Tesororo, docto: Iosé M!. Garrido Gómez, reele jido.

Vocal, doctor Hugo Flórez Moreno.

Secretario, doctor Eduardo Acosta Bendek, realegido.

Con anticipadas gracias por la favorable acogida que ustedes se sirvan dispensar a esta información, nos es 
grato quedar como sus afuctísimos amigos y colegas,

\section{Dr. Eduardo Acosta Bnndek} Secretario.

Rosario, enero 22 de 1953

wor Presidente de la Sociedad

Obstetricia y Cinecolajiu de Colombia. Apartado Nacional 276. Bogotá.

De nuestra mayor consideración:

Tenemos el agrado de comunicar a usted y por su intermedio a la Sociedad de su digna presidencia que ha :ido elegida para regir loc destinos de esta Sociedad de Obstetricix y Ginecología de Rosario, por el período 1953-1954, la Comisión Directiva intearada en la siguiente forma:
Presidente, doctor Ricardo B. Mon. Vicepresidente, doctor Luciano A. Belizán.

Secretario General, doctor Rodollo Pecorone.

Secretario de Actas, doctor Bernar do Schaffer.

Director de los boletines, doctor Iu ho C. Gosende.

Tesorero, doctor Antonto R. Manzoni.

Bibliotecario, dóctor Alejandro García Loza.

Vocales titulares. doctores: Rafael M. Pineda, Adolfo G. Lavarello.

Vocales suplentes: doctores Pedro Figueroa Casas, Felipe S. Morello.

Sin otro particular, lo saludan muy atentamente,

Dr. Ratael M. Pineda

Presidente.

Dr. Felipe S. Morello

Secretario General. 